\title{
KEKERASAN PSIKO-SOSIAL DALAM PENDIDIKAN DAN KENISCAYAAN BIMBINGAN KONSELING
}

\author{
Andi Mappiare-AT \\ Jurusan Bimbingan dan Konseling Universitas Negeri Malang \\ e-mail: andi_mappi@yahoo.com
}

\begin{abstract}
Violence in any form and reason specifically in educational setting will affects every individual. Teachers should be aware that violence has historical cycle in society, community, even in individual levels. Based on the consideration, this paper tries to: 1) understand the root of violence, its values and its personal and social characteristics; 2) recognize the social characteristics of patriarchy and matriarchy in educational setting, and the necessity for counselors of having matriarchal communication styles; and 3) assert the importance of school counselors to equip themselves with balanced, empathic, and mutual communication. This paper concludes that the root of violence is not inherent in human nature but socially learned and inherited. Secondly, matriarchal characteristics in social relations are needed to prevent violence. Third, school counselors should equip themselves with mutual communications.
\end{abstract}

Keywords: School counselor, matriarchy, patriarchy, violence

\begin{abstract}
Abstrak: Kekerasan bentuk apapun, dalam latar manapun, khususnya dalam dunia pendidikan, membawa dampak merugikan bagi banyak pihak. Para pendidik perlu menyadari bahwa kekerasan memiliki siklus historis baik pada kesatuan sosial terbesar, komunitas terbatas, maupun individu. Atas dasar itu, tujuan kajian ini adalah: pertama, mengenali 'akar kekerasan', sifat personal, sifat sosial, dan nilai yang dikandungnya untuk dapat dipahami dan dikelola; kedua, mengenali keberadaan sifat-sifat sosial patriarki dan matriarki dalam institusi pendidikan, serta bagaimana keniscayaan komunikasi konselor di bawah sifat matriarki; ketiga, pentingnya konselor/Guru Bimbingan Konseling (BK) melengkapi diri dengan komunikasi berimbang, empatik, saling berbagi, dan saling memenuhi kebutuhan. Setelah melalui kajian konseptual, tulisan ini menyimpulkan bahwa: pertama, 'akar kekerasan' adalah tidak melekat pada hakekat manusia, melainkan terkandung dalam sifat sosial yang dipelajari dan diwariskan secara sosial; kedua, keberadaan sifat sosial dan sifat matriarki (pengganti yang patriarki) adalah niscaya adanya untuk mencegah kekerasan; dan ketiga, konselor perlu melengkapi diri dengan komunikasi berimbang.
\end{abstract}

Kata kunci: Konselor, matriarki, patriarki, kekerasan

Banyak guru memiliki sifat-sifat tulus (genuine), rela-berkorban (altruistic), dan empati, dengan aksi psiko-sosial lembut, penyayang, dan mengasih-asuh siswa. Namun akhir-akhir ini, dalam upaya yang disebutnya 'mendidik' atau membimbing untuk 'mendisiplinkan anak', ada saja guru dengan aksi psiko-sosialnya yang sangat 'unik'. Tidak sedikit yang sangat berbeda jauh dari prinsipprinsip pendidikan dan bimbingan. Teknikteknik bersifat 'mengarahkan' seakan sudah tidak mempan untuk memodifikasi perilaku anak. Teknik-teknik cukup netral atau mendukung yang sifatnya lebih lunak jarang digunakan. Upaya terakhir pengubahan perilaku siswa yang dipilih guru tersebut adalah cara kekerasan. Teknik bersifat directing seperti advising, punishing, teaching, coaching, dan encouraging, digantinya dengan 'student-fighting' (mengadu anak), peristiwa bullying dan perkelahian pelajar yang sering terjadi 
antarsiswa mungkin tidak terlepas dari perilaku tidak layak sebagian guru yang mengaku "pendidik".

Apakah pendidik kehabisan teknik? Rasanya tidak, mereka telah belajar teknik secara lebih dalam tentang pendidikan formal dan penataran, mencapai "belajar lebih" atau 'overlearning'. Konsepsi "belajar lebih" (overlearning), dalam psikologi belajar, adalah proses dan hasil latihan subjek dalam kualitas lebih dari tuntutan tujuan belajar. Teknik "belajar lebih" biasanya dilakukan agar subjek memiliki kompeten unjuk-kerja dalam situasi nyata yang lebih kompleks dari situasi buatan ketika latihan. Hal ini berkaitan dengan sifat-sifat sosial yang diperoleh (aquisition), dan yang sering disebut "karakter sosial", yang dimiliki sebagian guru itu. Sifat-sifat sosial patriarki (patriarchy) -keras, menguasai, otoritatif -lebih ditampilkan oleh sejumlah guru dalam aksi sosial 'mengajar' mereka, banyak yang jauh dari mengajarkan nilai-nilai kebajikan. Sifatsifat sosial matriarki (matriarchy) -lembut, membebaskan, demokratik - meskipun dimiliki dan diterapkan oleh banyak guru dalam aksi sosial mendidiknya, namun tidak terlalu nampak ke permukaan. Era keterbukaan informasi membawa media massa lebih intensif memberitakan hal yang ekstrem, misalnya kekerasan, daripada kelembutan.

Kekerasan terjadi bukan dalam bidang pendidikan saja. Kekerasan dalam berbagai jenisnya (fisik, psikis, verbal) agaknya juga banyak terjadi dalam bidang-bidang lain, misalnya hukum, bisnis, politik, bahkan bidang pemerintahan Indonesia masa lalu. Suatu analisis 'kritik diagnostik' (Kellner, 2003d) dapat ditelusuri 'histori kekerasan' dalam sosial budaya Indonesia masa kini. Kritik diagnostik menggunakan penelusuran hakekat pemaksaan biologis, kekerasan fisik, tekanan psikis, dan tekanan sosial, melalui pengkajian historis suatu kaum sebagaimana pernah dilakukan seorang pakar teori kritik (Fromm, 2001; 2002b).

Fromm mengulas, tentang bagaimana pengalaman bangsa Yahudi menerima perlakuan penuh kekerasan, terusir dari tanahnya, diburu dan dibunuh, diperbudak sejak abad ke-7 SM, mulai dari perampasan tanah mereka oleh bangsa Babilon, serbuan bangsa Romawi, sampai abad ke-20 M. Lebih dari sepertiga mereka dibunuh oleh Nazi Jerman. Fromm kemudian sampai pada suatu pemahaman: "Apakah tidak alami jika mereka memupuk kebencian kepada penindas mereka dan menjadi suku nasionalistik yang mudah bereaksi dan bertindak primordial kesukuan untuk membenarkan kehinaan kronis mereka?" (Fromm, 2002b: 109 - 110). Namun, persoalannya bukan pada balasmembalas kekerasan dan pengerusakan, ataukah soal makna perjuangan untuk menjadi pembenar suatu aksi kekerasan. Soal intinya adalah ada histori sosial dari kekerasan, sebagaimana dibahas nanti, dimana Fromm memberikan keyakinan. Begitupun bahwa "kekerasan" memiliki koneksitas dengan sifat-sifat patriarkis, yang disebutnya "karakter patriarki" suatu komunitas (Fromm, 2001).

Sebuah tesis doktor pada Monash University (Australia) telah mengangkat kajian mengenai wacana kekerasan negara Indonesia terhadap rakyat pada zaman pemerintahan Orde Baru. Diulas cukup detail di antaranya pembuangan tanpa pengadilan eks PKI ke Pulau Buru, penangkapan aktivis mahasiswa, interegosi dengan kekerasan, rekayasa hukum untuk memenjarakan aktivis yang dicurigai dan diwacanakan sebagai 'ekstrem' atau 'subversif' (Heryanto, 1993). Sebuah analisis lain juga menunjukkan bahwa bahasa, diskursus dan semantika, misalnya 'partisipasi', 'pembangunan', pada zaman Orde Baru Indonesia, lebih banyak digunakan untuk memperdaya (eksploitasi) dan kontrol negara atas rakyat daripada pemberdayaan 
(Leigh, 1999). Analisis secara terpisah Ariel Heryanto dan Barbara Leigh itu memang tidak bermaksud melakukan refleksi kekerasan orang Indonesia sekitar dan setelah era Reformasi sampai kini. Namun, dengan meminjam perspektif historis dan analisis kritik diagnostik Fromm, dapat pula diduga bahwa kekerasan sejumlah insan bangsa Indoneisa khususnya dalam bidang politik kini, mungkin berkaitan dengan kekerasan negara dalam kajian "state-terrorism" yang dimaksud Heryanto.

Dengan pendirian bahwa kekerasan dalam bentuk apapun dan latar belakang apapun adalah tidak dapat dibenarkan, bahasan ini bermaksud agar pendidik pada akhirnya menyadari bahwa suatu komunitas atau individu yang pernah mengalami kekerasan dalam proses pendidikan, akan juga mengembangkan aksi kekerasan yang dirasionalkan. Kekerasan memiliki siklus historis baik pada kesatuan sosial terbesar, komunitas terbatas, maupun individu. Kekerasan harus diputuskan siklusnya melalui pendidikan yang diwarnai sifat-sifat kultur matriarki. Bimbingan konseling (BK) adalah tumpuan utama dalam upaya memutuskan siklus kekerasan. Kahadiran program BK, tidak diragukan lagi, adalah sangat niscaya adanya dalam kondisi sosial budaya Indonesia masa kini, khususnya dalam memutuskan siklus historis akar kekerasan dengan cara mensyiarkan sifat-sifat dari kultur matriarki.

Atas dasar latar belakang di atas, dibahas tiga poin penting selaku fokus kajian: Pertama, mengenali kembali 'akar kekerasan', karakter sosial, ciri-ciri, dan sifat yang dikandungnya untuk dapat dipahami dan dikelola; Kedua, keberadaan sifat-sifat sosial (dari kultur atau "karakter sosial") patriarki dan matriarki dalam institusi pendidikan; bagaimana keniscayaan komunikasi konselor di bawah sifat matriarki; Ketiga, pentingnya kehadiran Konselor/Guru BK di sekolah yang telah diperlengkapi dengan komunikasi berimbang, empatik, saling berbagi (sharing), dan saling memenuhi kebutuhan.

\section{PEMBAHASAN}

Tiga fokus kajian yang tersebut dalam paragraf akhir di atas dibahas dalam bagianbagian berikut ini.

\section{Akar Kekerasan, Sifat Sosial, dan Ciri- cirinya}

Apa yang dinamakan "sifat sosial" di sini, dinamakan oleh Formm sebagai "Karakter sosial" ('social character'). Secara teoretik dan umum, seturut Fromm, karakter didefinisikan sebagai suatu sistem pengisian energi hidup, elan vital, dimana manusia mengatur baik hubungannya dengan orang lain maupun dalam cara-caranya memadukan diri dengan alam, untuk pemuasan kebutuhan material. Oleh karena karakter adalah suatu sistem maka setiap sifat dari karakter adalah berkaitan satu sama lain, dan suatu sifat tunggal tidak dapat berubah tanpa pengubahan dalam keutuhan sistem. Sistem karakter merupakan patokan dasar perilaku, dan faktor inilah sebagai pembeda individu satu dari lainnya. Apa yang umum dimiliki semua orang, jelas Fromm lebih lanjut, fisiologis dasar sebagai akar impuls seperti dimaksudkan oleh konsep terkenal Paul Maclean, yaitu 4-F: "feeding, fighting, fleeing and ... the performance of sexual activities. " Namun, kata Fromm, cara pemuasan impuls itu adalah dimediasi oleh karakter; dan tidak saja oleh dorongan fisiologis yang dikondisikan tapi juga pemuasan itu berakar di dalam kespesifikan kondisi manusia, seperti kebutuhan akan kerangka orientasi dan penyerapan, kesan identitas, rasa mampu menggerakkan orang lain atau sesuatu (Fromm, 2004).

Atas dasar keyakinan itu, Fromm 
mengembangkan banyak konsepsi dan proposisi mengenai karakter individu dan karakter sosial, serta koneksitasnya dengan kekerasan atau pengrusakan. Dalam tulisan ini dibedakan secara tajam antara konsepsi "keseluruhan sistem sosial-pribadi yang utuh" yang disimbolkan dengan istilah "karakter" dengan "unsur-unsur khusus karakter disimbolkan dengan istilah "sifat". Dengan demikian, dapat disoroti secara lebih tajam bahwa (misalnya) kecenderungan 'dominasi', 'submissif', 'patriarki', atau 'matriarki' adalah sifat-sifat; sementara paduan utuh daripada unsur-unsur sesifat itu adalah karakter. Ketika sesuatu sifat pribadi berkembang dan dimiliki bersama sampai menjadi ciri khas suatu komunitas maka sesuatu sifat itu berubah menjadi 'kultur'. Dengan proses ini dapat muncul konsepsi 'kultur patriarki', 'kultur matriarki', dan seterusnya.

Dalam penelusuran ikhwal "akar kekerasan", dan koneksitasnya dengan karakter, dapat dikaji dari beberapa pandangan Fromm. Salah satu ungkapan Erich Fromm yang sangat mendasar dan diangkat kembali oleh George Bueree, adalah dalam suatu kalimat: "In reality, nearly everyone in a traditional society learns both how to dominate and how to be submissive, since nearly everyone has someone above them and below them in the social hierarchy" (Boeree, 2006). Tegasnya, bahwa dalam kenyataannya hampir semua orang belajar bagaimana mendominasi atau bagaimana menjadi penurut karena hampir semua orang berada dalam posisi dalam mana ada seseorang di atasnya atau di bawahnya di dalam masyarakat manusia yang pada hakikatnya adalah berkelas-kelas, bersusun, berpelapisan sosial.

Atas pandangan itu, Fromm mengeritik beberapa pendekatan mengenai "akar kekerasan" dan agenda "modifikasi perilaku sosial" yang ditawarkan beberapa peneliti, pemikir, sampai para filosof. Ada beberapa pandangan mengenai hakekat keagresifan, kekerasan, dan pengrusakan pada manusia yang dikritisi oleh Fromm (2007). Kritik Fromm terhadap berbagai pandangan, dalam bentuk dan sistematika lain, ditemukan pula dalam karya Fromm yang lain (Fromm, 2001). Salah satu pandangan yang dikritiknya adalah yang dikemukakan oleh filosof Pencerahan Prancis yang berpandangan bahwa manusia secara alamiah adalah baik namun peristiwa sosial telah merusaknya. Pandangan kedua, yang dikemukakan oleh banyak ahli psikologi, meyakini keagresifan-pengrusakan bukanlah instink -baik dalam tinjauan Freudian ataupun dalam analisis Konrad Lorenz- dan hal itu tidak melekat pada karakter dasar manusia, melainkan lebih sebagai sifat yang dipelajari. Dari segi metodenya, pandangan ini merupakan teori sebagai elaborasi lebih ilmiah daripada yang dikemukakan dalam era Pencerahan. Pandangan ketiga, aslinya dikemukakan oleh John Dollard dan koleganya, bahwa agresi senantiasa merupakan akibat dari frustrasi. Ini berarti bahwa jika orang tidak frustrasi maka orang tidak bersifat agresif; atau dengan kata lain, agresi itu tidak melekat pada hakekat manusia. Setelah mengemukakan kelemahan tiap teori itu, kemudian dikatakan: "Any attempt to find explanations for the causes of human violence must begin by distinguishing various kinds of aggressiveness which are qualitatively different from each other and which have entirely different sources" (Fromm, 2007).

Fromm menyebutkan banyak sekali jenis sifat agresi, lebih dari 20 nama sifat khusus, misalnya adaptif antarspesies, bawaan/melekat, defensif, destruktif, instingtifistik, instrumental, interspesifik, intraspesifik, dan seterusnya (Fromm, 2001). Berbagai jenis keagresifan dikategorikannya dan disajikan dalam garis-garis besar: (1) tipe sangat luas dari keagresifan adalah reaktif dan difensif. Setiap hewan menampakkan 
keagresifan tipe ini ketika menyangkut minat vital, yaitu kehidupan, teritori, makanan, melindungi anak, dan akses pada yang betina. (2) Keagresifan reaktif yang sangat khas adalah yang disebut lustful destructiveness, secara khusus ada pada manusia dan tidak bermaksud survival -secara biologis maupun sosial- namun menghasilkan kenikmatan gairah yang sangat mendalam. Contoh paling terkenal dari agresi gairah nafsu adalah yang disebut sadisme, cara mendapatkan kenikmatan melalui menghinakan orang orang lain secara fisik dan sosial. (3) Sebagai lawan dari 'lustful destructiveness' adalah nekrofilia, yaitu atraksi terkait kematian, pembusukan, dan kesakitan dalam bentuk seksual dan non-seksual (Fromm, 2001). Namun, Fromm juga menegaskan: "Although the various types of aggressivenessdestructiveness differ in quality and origin, they often overlap. It is especially important to note that there is a trigger mechanism which leads to the outburst of lustful destructiveness or necrophilia as a result of reactive aggressiveness" (Fromm, 2007).

Setelah melakukan sejumlah kritikan yang menunjukkan kelemahan berbagai teori mengenai akar kekerasan, Fromm mengajukan agenda perubahan sosial atau 'modifikasi karakter sosial'. Satu-satunya cara yang ampuh, menurut Fromm, yang dikenal sebagai humanis, yaitu 'pemanusiaan masyarakat teknologik'. Maksudnya, masyarakat harus menyediakan pemenuhan kebutuhan manusia berupa perhatian, kepedulian, peran-serta positif dalam masyarakat, misalnya dalam kerja, daripada sekedar menciptakan alat untuk produksi dan konsumsi, apalagi sekedar tekanan-tekanan peraturan dan hukum. Erich Fromm mengajukan keyakinan proposisional bahwa "Stricter punishment and enforcement of law and order will not reduce violence; on the contrary, it will increase violence because it will create new resentments, hostilities, and frustrations in those exposed to the organized violence of the state" (Fromm, 2007).

Dalam mengelaborasi isu akar kekerasan tersebut di atas, sebagai contohnya di sini akan diambil inti-inti kritik Fromm tehadap teori Konrad Lorenz, seorang ahli etologi. Teori Lorenz menekankan 'sifat hidrolik' dari agresi (agresi adalah tekanan dari dalam) dan memandang agresi manusia sebagai warisan sebagaimana pada hewan. Teori Lorenz juga menekankan adanya peran agresi yang menimbulkan cinta, "tiada cinta tanpa agresi", juga mengenai pentingnya nilai ikatan pribadi dan persahabatan pencegah agresi. Dalam hal ini, Fromm mengajukan konsep utama tentang pentingnya "pengetahuan empatik yang mendalam". Seturut Fromm, "kesalingkenalan" dan "persahabatan" tidak dapat diharapkan untuk meredam agresi, karena keduanya sama dengan pengetahuan semu tentang suatu "objek" yang dilihat dari sisi luar. Ini sangat berbeda dengan pemahaman empatik, jelas Fromm lebih lanjut, dimana seseorang memahami pengalaman orang lain dengan berpedoman pada pengalaman pribadi yang, jika tidak sama persis, tentu ada kemiripannya. Jenis pemahaman empatik akan meningkatkan pemahaman objektif. "Pencapaian pemahaman objektif dapat menurunkan atau menjauhkan keagresifan" (Fromm, 2001: 26-27). Dimensi sebaliknya dari kekerasan tidak sekedar non-agresif melainkan hubungan persaudaraan, dan sentralnya unsur cinta: “...hubungan persaudaraan hingga mendekati prinsipprinsip paling otentik dalam kehidupan tetaplah cinta" (Fromm, 2002a: 239). Pada intinya, Fromm menekankan bahwa kekerasan tidak bisa diatasi melalui hukumhukum legal kuat, melainkan dengan cara mengkreasi suatu masyarakat dalam mana orang-orang berkoneksi satu sama lain sebagai layaknya manusia dan (manusia) mampu mengontrol kehidupan mereka sendiri 
(Fromm, 2007).

Teori karakter sosial, khususnya yang terkait dengan jenis kelamin dan gender, dan enkulturasi sosial secara 'total' (religi dan ideologi, sosio-ekonomi dan khususnya sosio-kultur) dikaji oleh Fromm secara intens (Fromm, 2001; Fromm, 2002a; Kellner, 2003b). Fromm bertolak pada kategori kultur 'patriarki' dan 'matriarki' dari teori Johann Jacob Bachofen mengenai karakter masyarakat yang mewariskan nilai-nilai melalui pendidikan, khususnya keluarga. Kultur 'matriarki' adalah lebih banyak mengandung ciri-ciri positif; sementara kultur 'patriarki' adalah lebih banyak mengandung ciri-ciri negatif (Fromm, 2001: 214-216). Jika kultur telah menjelma menjadi karakter sosial maka karakter atau sifat-sifat matriarki banyak mengandung nilai-nilai mulia, baik, kebajikan; sementara sifat-sifat (karakter) patriarki banyak mengandung nilai buruk, keburukan. Kultur 'matriarki' (oleh Bachofen dalam tafsir Fromm) adalah ekuivalen dengan karakter masyarakat 'demokratik-egalitarian', dan kultur 'patriarki' adalah ekuivalen dengan karakter 'otoritatif-eksploitatif' (Fromm, 2001). Konsepsi ini pernah diulas khusus dalam kajian karakter institusi atau lembaga pendidikan (Mappiare-AT., 2009).

'Keluarga' dipandang oleh Fromm sebagai struktur sentral yang menjadi medium 'pewarisan' karakter sosial dan identitas individu. Fromm sebagai pemikir yang berbasis psikoanalisis neo-Freudian $\sim$ dan mensintesiskannya dengan konsepsi Karl Marx mengenai peran ekonomi, kepemilikan sebagai power $\sim$ menempatkan keluarga sebagai struktur sosial utama yang mempengaruhi perkembangan individu. Dalam ulasan Douglas Kellner, Fromm yakin benar bahwa keluarga merupakan perantara dimana masyarakat atau kelas sosial menanamkan atau mewariskan struktur khususnya kepada anak. Aslinya berbunyi: "the family is the medium through which the society or the social class stampt its specific structure on the child" (Kellner, 2003a). Dinamika karakter keluarga dan proses sosialisasi dapat mengindikasikan bagaimana masyarakat mereproduksi struktur kelasnya dan memaksakan ideologi dan praktikpraktiknya kepada individu, dan kemudian menjadi identitas atau sifat-sifat individu. Melalui pengungkapan banyak hal positif kultur matriarki, dan banyak aspek negatif dalam kultur 'patriarki', Fromm menyugestikan proses enkulturasi secara 'total' berlangsung secara positif melalui kultur matriarki dimana semua orang dapat berpartisipasi dalam religi dan ideologi, sosioekonomi dan khususnya sosio-kultur, sehingga kebutuhan dasar semua manusia terpenuhi (kajian bentuk lain mengenai hal ini dalam kaitannya dengan pembentukan identitas perempuan Islam pemakai jilbab telah diuraikan dalam Mappiare-AT., 2009).

'Matriarki', sebagai bukan 'patriarki', ditandai prinsip pegangan yaitu realisasi kreativitas bukan disiplin formal, prinsip egalitarian bukan otoritarian, memberdayakan (empowerment) bukan memperdaya (exploitative), pemerdekaan bukan penjajahan, pembebasan teleologis bukan pembatasan membabi-buta. Dalam hubungan pendidikan, pembimbingan, dan konseling, sifat matriarki memiliki ciri hubungan nonformal yang luwes bukan formal-kaku, hubungan pembelajaran personal bukan mengajar yang menuntun yang statis, pemenuhan sendi-sendi hubungan intersubjektif bukan hubungan otoritariansubmissif, hubungan pemenuhan ekspektasi mutualistik bukan pemenuhan ekspektasi salah satu subjek, relasi subjek-subjek bukanlah relasi objeksi yang satu atas yang lain, yang merupakan kebalikan (feedback) afektif-kognitif bukan kognitif-aksi semata; iklim/atmosfir psikososial ditandai suasana rileks bukan ketegangan (strain), ketentraman bukan rasa tertekan (stress), pemberian 
peluang (enabling zone) dan bukan penindasan (coersion), menonjol kebesaranhati subjek yang dibimbing daripada membesarkan diri pembimbing. Ciri-ciri matriarki atau patriarki sangat dapat diidentifikasi dalam hubungan pengajaran, pembimbingan dan (terutama) konseling.

\section{Patriarki-Matriarki dalam Institusi Pendidikan: Komunikasi Konselor adalah Matriarki}

Sekarang, seharusnya semua manusia yang bertautan dengan profesi pelayanan lebih menyadari 'modus operandi' ideologi patriarkal yang secara 'asyik' merasuki diri dan kiprah profesional. Sebagaimana diingatkan oleh sejumlah antropolog antiFreudian, bahwa dalam berbagai sisi kehidupan modern sangat rentan adanya nuansa perbudakan (slavery) dan rayuan tipudaya (seduction), misalnya pada subjek pasien/klien, murid, dan konsumen selaku 'modus operandi' ideologi patriarkal (O'Nell, 2001: 120-121). Namun menarik untuk ditampilkan pernyataan "tandingan" dari Peter Berger bahwa "program 'konseling', 'bimbingan', dan 'terapi' yang begitu banyak dikembangkan dalam berbagai sektor kehidupan institusional pada jaman ini sangat memperkuat aparat sebagai kontrol masyarakat secara keseluruhan, dan terutama wilayah-wilayah di mana sanksi sistem politico-legal tidak dapat dipergunakan" (Berger, 1985: 107).

Kutipan di atas tidak berarti bahwa bimbingan dan konseling tidak diperlukan karena seolah-olah memperpanjang kontrol atau opresi penguasa. Persoalannya adalah aksi dan interaksi yang ditunjukkan oleh kebanyakan personel yang bergerak di bidang pelayanan kemanusiaan (pendidikan khususnya) banyak yang menunjukkan buktibukti kebenaran pernyataan Peter Berger. Sementara di bawah konsepsi "supra struktur ideologik" pelayanan dalam bidang pendidikan dan bimbingan, khususnya, ditanamkan melalui pendidikan formal dan pelatihan-pelatihan ekspresi sikap altruistis, hangat, peduli, dan berbagai konsepsi sifatsifat matriarki. Sudah lebih dari 100 tahun perjuangan 'gender', namun karena kokohnya penguasa di mata subjek yang dikuasai, kokohnya otoritas guru dalam klaim kebenaran di mata murid atau siswa yang 'tak berdaya'; sampai tak terbilang banyaknya penelitian dan kajian dalam tulisan ilmiah, seminar dan lokakarya, masih terasa sulit terbentuknya komunitas matriarki yang mengandung nilai humanis, kesetaraan atau egaliter, peduli, empati, penuh asih-asuh, sebagaimana ciri masyarakat ideal yang disebut 'humanistic communitarian socialism' oleh Erich Fromm, sebagaimana yang diungkapkan oleh George Boeree: "Humanistic means oriented towards human being .... Communitarian means composed of small communities (Gessellschafted, in German).... Socialism means everyone is responsible for the welfare of everyone else" (Boeree, 2002: 8).

Banyak ciri-ciri positif dan nilai mulia, baik, kebajikan, pada komunitas matriarki dibandingkan ciri-ciri komunitas patriarki, sangat ditekankan oleh Fromm dan ditekankan kembali oleh penganutnya dalam wacana teori kritik (Lihat, Kellner, 2003c: 3 5). Dengan demikian, cukup signifikan harapan bahwa bimbingan dan konseling yang berkultur dan bersifat 'matriarki' akan lebih banyak ciri-ciri positifnya untuk kepentingan siswa daripada yang berkultur dan bersifat patriarki. Dalam konteks pendidikan, khususnya bimbingan, ini sangat nyata terkait dengan pengembangan pribadi, pemberdayaan, dan pemandirian siswa.

Pengembangan pribadi, pemberdayaan, dan pemandirian siswa adalah pekerjaan berat bila dilakukan tanpa transformasi kultur dan iklim/atmosfir komunitas dari atmosfir 
patriarki ke atmosfir matriarki. Sebagai klarifikasi, ditegaskan bahwa,'matriarki' (matriarchy), dan lawannya 'patriarki' (patriarchy) menunjuk pada kultur dengan iklim atau atmosfir sosiopsikis hubungan antarmanusia, atau iklim psikis komunitas, masyarakat. Meskipun 'matriarki' berasal dari sifat-sifat 'mama', 'ibu', namun sebagai kultur yang mendasari suatu iklim sosio-psikologis, hal itu dapat dimiliki pula oleh laki-laki; sebagaimana halnya, kultur 'patriarki' dapat dimiliki oleh perempuan (bahkan, dalam berbagai situasi, ada perempuan yang tampil lebih patriarki daripada laki-laki). Konsepsi ini menyerupai, dalam arti tidak sama persis, dengan konsepsi feminin-maskulin, dan karenanya dapat ditransfer pemaknaannya. Dalam wacana feminin-masukulin dikenal adanya konsepsi kepribadian androginis. Orang yang androginis dinyatakan terbukti lebih sehat. "Androgenous people (those who combine qualities of both the 'feminine' and the 'masculine') appear to be mentally healthier" (Boeree, 2006). Dengan demikian, matriarki bukanlah kultur dan sifat monopoli jenis kelamin perempuan. Lelaki pun dapat bersifat dan menciptakan iklim matriarki (matriarchy), sebagaimana laki-laki dapat bersifat 'keibuan'.

\section{Keniscayaan Hadir Bimbingan Konseling: Komunikasi Berimbang}

Pendidikan Sekolah secara riil memerlukan hadirnya Bimbingan dan Konseling (BK). Sifat yang melekat pada BK yang membuatnya diperlukan, tidak hanya karena teknik komunikasi yang telah dimiliki oleh Konselor atau Guru BK melainkan yang lebih penting karena filosofi mengenai hakekat manusia sosial, interaksi, dan komunikasi. Berbeda dengan Konselor/Guru $\mathrm{BK}$, sedikit guru matapelajaran memiliki pengetahuan filosofi sehingga kompetensi pedagogik dan teknik komunikasi yang telah dikuasai guru melalui "belajar lebih" (overlearning), belum dapat ditunjukkan secara layak dan konsisten oleh mereka. Ini semua merupakan dimensi individual dari kompetensi manusia sosial.

Manusia adalah makhluk individu dan juga makhluk sosial, dan karenanya juga perlu bersikap sosialis. Keseimbangan adalah suatu kondisi yang sangat penting, baik antara individu dengan masyarakat, maupun antara individu dengan individu dalam berkomunikasi. Mengenai kesembangan manusia sebagai individu dan anggota masyarakat, pernah diungkapkan oleh Einstein, seorang fisikawan, dengan kalimat:

Man is, at one and the same time, a solitary being and a social being. As a solitary being, he attempts to protect his own existence and that of those who are closest to him, to satisfy his personal desires, and to develop his innate abilities. As a social being, he seeks to gain the recognition and affection of his fellow human beings, to share in their pleasures, to comfort them in their sorrows, and to improve their conditions of life. Only the existence of these varied, frequently conflicting strivings accounts for the special character of a man, and their specific combination determines the extent to which an individual can achieve an inner equilibrium and can contribute to the well-being of society (dalam Boeree, 2006).

Dengan demikian, aplikasi inti sarinya yaitu, cara paling sentral untuk menunjukkan keseimbangan pribadi-sosial seorang guru, pendidik, adalah melalui hubungan antarpribadi dan interaksi sosial. Hubungan antarpribadi yang sehat atau menyehatkan kedua pihak yang terlibat dapat terjadi hanya dalam komunikasi yang berimbang. Ini sangat sejalan dengan konsepsi-konsepsi klasik, yaitu bahwa hubungan antarmanusia yang 
berimbang ditandai: Pertama, 'pemenuhan secara mutual' atau "mutually fulfilled" antara dua pihak; Kedua, 'posisi komplementer' atau "complementary positions" (Saxton, 1968) atau keseimbangan 'pribadi dan pengaruh posisional' atau "personal and positional influences" (Hansen, 1969). Dalam tataran teknis operasionalnya, atas konsepsi-konsepsi ini, komunikasi berimbang ditandai oleh situasi empatik, saling berbagi, saling memenuhi kebutuhan. Hal ini semua telah dipelajari secara tuntas dan diterapkan dalam kiprah profesional para Konselor atau Guru BK sebagai pemangku tugas Bimbingan dan Konseling sekolah.

Teori keseimbangan dalam hubungan antarpribadi ini ternyata memiliki daya transfer luas pada berbagai aspek kehidupan profesi, tidak saja bermanfaat untuk kehidupan praktis manusia yang berinteraksi. Metode 'interexperience' oleh R. D. Laing, sebagai aplikasi 'keseimbangan hubungan antarpribadi', merupakan metode yang sangat efektif dalam pemahaman konsepsi kepribadian (dalam Monte, 1995: 477-478). Itu sama efektifnya dengan metode intersubjektif atau verstehen dari Weber untuk hidup saling memahami, intersubjektivitas, dan pada dasarnya bertolak pada keseimbangan hubungan antarpribadi.

Keseimbangan dalam hubungan antarpribadi, khususnya dalam hubungan berpasangan, sejak lama dirumuskan oleh konselor perkawinan,yaitu terdapat tipe ideal keluarga menurut 'pemenuhan secara mutual' yaitu "dominance-submission needs, nurturance-dependence needs, achievementvicarious needs, dan hostility-abasement needs" (Saxton, 1968: 208-210). Sementara itu, Hansen merumuskan 4 tipe hubungan antarapribadi berdasarkan 'posisi komplementer' atau segi 'pribadi dan pengaruh posisional': “(a). Strong in both personal and posisional influence; (b). Strong in personal but weak in positional influence; (c). Strong in positional but weak in personal influence; (d). Weak in both personal and positional influence" (Hansen, 1969: 84). Ternyata, hubungan utuh yang kuat dan langgeng, bermanfaat bagi mereka yang terlibat dalam lingkungannya yaitu hubungan antarpribadi yang seimbang antara pribadi dan pengaruh posisional tiap pihak (Hansen, 1969: 84-85). Hubungan-hubungan semacam inilah yang kemudian diturunkan di sini menjadi ciri khas hubungan antarapribadi konselor-konseli atau Guru BK dan para siswa. Hubungan-hubungan 'model keseimbangan' yang saling memberdayakan semacam inilah sangat potensial disebarluaskan oleh para Konselor/Guru BK di sekolah.

Jika 'model keseimbangan' dalam hubungan antarpribadi ditularkan oleh para Konselor/Guru BK kepada para guru matapelajaran maka kekerasan dalam dunia pendidikan akan dapat dieleminasi. Salah satu langkah berikutnya adalah dengan melatihkan 'model keseimbangan' dalam komunikasi itu kepada mahasiswa calon guru. Ini memungkinkan mereka dapat mentrasfer prinsip dan keterampilan 'hubungan seimbang yang mendalam' antara konselor dan konseli dalam melaksanakan pembelajaran sebagai guru patapelajaran kelak. Hal demikian pernah dikaji secara mendalam berupa label "intersubjective" dalam dialog konseling, baik dalam psikoanalisis maupun ancangan/pendekatan lainnya (Gerhardt, Sweetnam, \& Borton, 2000). Sudah barang tentu tronsformasi suasana interaksional konseling (konselor-konseli) ke dalam suasana pembelajaran (guru matapelajaransiswa) perlu dilakukan.

Keseimbangan hubungan antarmanusia dapat dipraktekkan atau dilatihkan melalui kesadaran-diri dan kesadaran akan keberadaan atau eksistensi-diri pihak lain. Pelatihan secara kelompok yang dimaksudkan agar mahasiswa dapat memiliki 
keterampilan melakukan 'keseimbangan dalam hubungan antarpribadi memuaskan'. Seperangkat modul pelatihan dan prosedur pelatihannya dapat dirancang dan diujikan dalam penelitian pengembangan sebagaimana pelatihan "peer power" untuk menjadi helper efektif yang pernah dilakukan dalam aspekaspek lain komunikasi oleh Tindall dan Gray (1987).

Dari paparan di atas, diperlukan adanya: (1). Penetapan konsep operasional 'keseimbangan dalam hubungan antarpribadi' yang tidak semata sesuai dengan keperluan profesi konselor tapi juga yang menjanjikan hubungan antarpribadi yang memuaskan, serta teruji secara langsung dalam konteks pembelajaran. (2). Penyusunan format-format pelatihan hubungan antarpribadi seimbang dan memuaskan yang dicancang secara cermat dan teruji langsung di lapangan pada subjek yang memerlukannya, yaitu para guru matapelajaran. (3). Kehadiran Bimbingan dan Konseling sekolah, dimana Konselor/Guru BK sebagai petugas, merupakan hal penting dalam penularan komunikasi berimbang di sekolah.

\section{SIMPULAN}

Pertama, dapat dikenali bahwa 'akar kekerasan' pada manusia sesungguhnya tidak melekat pada hakekat manusia, baik secara biologis maupun psikis. Kekerasan terkandung di dalam sifat-sifat ("karakter") sosial dan diwariskan secara sosial melalui keluarga, institusi, bahkan profesi. Sifat-sifat sosial itu mempunyai ciri dasar sebagai sistem sehingga perubahan haruslah dilakukan secara total, sistemik. Agenda perubahan sosial adalah menuju masyarakat humanis dan berkultur matriarki yang memungkinkan terpenuhinya berbagai kebutuhan dasar manusia.

Kedua, keberadaan kultur sosial patriarki dan matriarki dalam institusi pendidikan harus jelas. Pelapisan sosial dalam institusi pendidikan-guru/konselor memiliki atasan dan juga bawahan-menjadi konteks yang menyuburkan operasi kultur patriarki, diikuti oleh tekanan atau opresi, pemaksaan atau koersi, dan bahkan kekerasan. Namun, kultur matriarki perlu lebih ditonjolkan dalam berbagai situasi interaksi sosial daripada kultur patriarki. Kultur patriarki kadang-kadang masih diperlukan dalam urusan institusional. Kultur matriarki yang ditandai komunikasi empati, penuh pemahaman, kepedulian adalah niscaya adanya dan hal demikian ini sangat memungkinkan disediakan oleh konselor atau guru BK jika didalam isntitusi pendidikan terdapat sifat-sifat matriarkis.

Ketiga, peran Konselor/Guru BK dengan komunikasi berimbang, empatik, saling berbagi, saling memenuhi kebutuhan-'model keseimbangan'-adalah sangat esensial kedudukannya. Jika 'model keseimbangan' dalam hubungan antarpribadi dilatihkan kepada para guru matapelajaran dan para mahasiswa calon guru matapelajaran, memungkinkan mereka dapat mentransfer prinsip dan keterampilan 'hubungan seimbang yang mendalam' antara konselor dan konseli ke dalam pelaksanaan pembelajaran khususnya dan interaksi manusia dengan para siswa pada umumnya. Akan tetapi, tidak hanya teknik komunikasi yang perlu dimiliki oleh guru matapelajaran melainkan yang lebih penting adalah filosofi manusia sosial, interaksi, dan komunikasi.

\section{SARAN}

Pertama, para peneliti disarankan mengkaji lebih jauh 'akar kekerasan', karakter, dan sifat-sifatnya, khususnya dalam konteks sosial budaya Indonesia. Manfaatnya adalah akan diperoleh pemahaman yang tuntas tentang 'akar kekerasan' dalam berbagai dimensi kehidupan dan kaitannnya dengan 
kultur patriarki dalam berbagai institusi dan organisasi.

Kedua, pembuat kebijakan pendidikan diharapkan mengambil kebijakan yang semakin meluangkan penambahan tenaga konselor profesional di sekolah, serta meluangkan penerapan kultur sosial matriarki dalam institusi pendidikan. Para tenaga profesional ini dididik untuk berkultur matriarki dan dapat diandalkan untuk mensosialisasikan masyarakat humanistis dalam institusi pendidikan.

Ketiga, para pendidik perlu mendalami filosofi mengenai hakekat manusia sebagai pribadi dan sebagai makhluk sosial. Kompetensi pelatihan komunikasi perlu dimiliki oleh Guru BK, konselor, calon konselor, namun itu saja belum cukup untuk menjalankan peran sebagai pendidik dengan kultur matriarki. Para pendidik perlu memiliki wawasan dan kecerahan filosofis mengenai hakekat manusia sosial sebelum diharapkan kompeten menularkannya kepada para guru mata pelajaran di sekolah.

\section{DAFTAR PUSTAKA}

Berger, P. (1985). Humanisme Sosiologi. (Edisi Terjemahan). Jakarta: Inti Sarana Aksara.

Boeree, C. G. Online. (2002). 'Erich Fromm $(1900-1980)^{\prime}$. Diakses dari http://www.ship.edu/ cgboeree/fromm.ht m1 pada 15 Januari 2002.

Boeree, C. G. (2006). 'Personality Theories'. D i a k s s d a r i http://webspace.ship.edu/cgboer/ conclusions.html pada tgl. 20 Desember 2006.

Fromm, E. (2001). Akar Kekerasan: Analisis Sosio-Psikologis atas Watak Manusia. (Edisi Terjemahan). Yogyakarta: Pustaka Pelajar.

Fromm, E. (2002a). Cinta, Seksualitas, Matriarki Gender. (Edisi Terjemahan). Yogyakarta: Penerbit Jalasustra.

Fromm, E. (2002b). Manusia Menjadi Tuhan: Pergumulan antara 'Tuhan Sejarah' dan 'Tuhan Alam'. (Edisi Terjemahan). Yogyakarta: Jalasustra.

Fromm, E. (2004). 'Theory of Aggression' dalam 'The Literary Estate of Erich Fromm' c/o Rainer Funk. Diakses dari h t t p : / / w w w . e r i c h fromm.de/data/pdf/1972c-e.pdf pada 14 Agustus 2007.

Fromm, E. Online. (2007). 'The Nature of Violence' dari 'Essay for Collier's Year B o o k'. D i a k s e s d a r i http://encarta.msn.com/sidebar_46151132 $9 /$ the_nature_of_vi o lence by_eric_fromm.html, pada 14 Agustus 2007.

Gerhardt, J., Sweetnam, A., \& Borton, L. (2000). 'The Intersubjective Turn in Psychoanalysis: A Comparison of Contemporarry Theorists', Psychoanalytic Dialogues, 10(1), 5-42.

Hansen, D., (1969). Explanation in Sociology and Counseling (Eds). Boston: Houghton Fifflin Company.

Heryanto, A., (1993). 'Discourse and StateTerorism: a Case Study of Political Trials in New Order Indonesia 1989-1990. A Thesis subbmitted for the degree of doctor of philosophy in the Departement of Anthropology Monash University, Australia. 
Kellner, D. (2003a). 'Erich Fromm Biography'. D i a k e s d a r i http://www.uta.edu/huma/illuminations/ kell8.html pada 25 November 2003.

Kellner, D. (2003b). 'Erich Fromm, Feminism, and the Frankfurt School'. Diakses dari http:/www.uta.edu/huma/illuminations/ kell8.html pada 25 November 2003.

Kellner, D. (2003c). Critical Theory and Crisis of Social Theory. Diakses dari http:/www.uta.edu/huma/illuminations/ kell8.html pada 25 November 2003.

Kellner, D, (2003d). Teori Sosial Radikal (Eds). Edisi Indonesia (Eko-Rindang Farihach), Yogyakarta: Syarikat.

Leigh, B., (1999). "Learning and Knowing Boundaries: Schooling in New Order Indonesia", SOJOURN, 14 (1), 34-56.

Mappiare-AT, A., (2009). Identitas Religius di Balik Jilbab: Perspektif Sosiologi Kritik. Malang: Penerbit Universitas Negeri
Malang (UM Press).

Monte, C. F., (1995). Beneath the Mask: An Introduction to Theory of Personality. For Worth, Philadelphia: Harcourt Brace College Publishers.

O'Neill, J. (2001). Psychoanalysis and sociology: From freudo-marxism to freudo-feminism. In G. Ritzer, \& B. Smart (Eds.). Handbook of social theory. (pp. 112-125). London: SAGE P ublications Ltd. doi : http://dx.doi.org/10.4135/97818486083 51.n10.

Saxton, L., (1968). The Individual Marriage, and the Family. Belmont, CA.: Wodsworth Publishing Company Inc.

Tindall, J. A., \& Gray, H. D., (1987). Peer Power: Becoming An Effective Peer Helper, Book 1: Introductory Program. Muncie, Indiana: Accelerated Developmment, Inc. 